\title{
Suicide Attempts as Social Goal-Directed Systems of Joint Careers, Projects, and Actions
}

\author{
Ladislav Valach, PhD, Konrad Michel, MD, R. A. Young, EdD, and P. Dey, MA
}

In the present study we examined to what extent persons who attempt suicide describe their attempt in terms of social, joint processes. Psychotherapists interviewed 40 patients hospitalized in a general hospital for a few days after an attempted suicide. The content of the interviews was analyzed for the level of systemic processes the patients referred to (that is, action, project, and career). The most common processes to which the patients referred were relationship careers and projects and conflicts and argumentative actions. Our analysis indicates that a social process can be found at all levels of the patient's organization of the suicide attempt, within a system of goal-directed action, project, and career.

Mental health practitioners and researchers call for self-efficacy, active coping, and personal agency with corresponding models in psychology and medicine (Bandura, 1986; Oakley, 2004), but these models are seldom utilized in conceptualizing negatively valued human processes and behaviors such as suicide. Suicidologists base their explanations on social context, which they see as causal, rather than on the joint, goal-directed action of those involved. Socially anchored explanations of suicide and suicide attempts are prime examples of the accounts based on social roots and social causes (Durkheim, 1897/ 1951; Maris, 1997).

Maris (1989) brought a new conceptu-

Ladislav Valach is in the Dept. of Psychopathology at the University of Zurich in Switzerland; Konrad Michel and P. Dey are in the Dept. of Community Psychiatry at the University of Berne in Switzerland; and R. A. Young is with the Dept. of Educational and Counselling Psychology and Special Education at the University of British Columbia in Vancouver, Canada.

Address correspondence to Ladislav Valach, Faculty of Philosophy, University of Zurich, Clinic Schloessli, 8618 Oetwil am See, Switzerland; E-mail: ladislav.valach@swissonline.ch alization of social processes in suicide to the discussion. He introduced the notion of social suicide. He located this notion between Durkheim's (1897/1951) conceptualization of suicide and the writings of Wittgenstein (1999), using terms such as emergent suicides or group suicide in the cases of mass suicide, organizational self-destruction, and witnessed suicide. He identified both the suicide of a social body as an analog to individual suicide and the suicide in which several persons are involved in a parallel or synchronized way and steered by a shared intention.

The aim of our study was to examine attempted suicide, and by inference suicide, as a part of goal-directed social process. Specifically, we asked to what extent patients, following a suicide attempt, described their attempt in terms of individual events and/or social processes. While there is a substantial preconception of suicide and suicide attempts as individual phenomena since the event itself frequently occurs when the person is alone, social processes are often identified in the narratives of suicide attempts. For example, relationship problems are often named as the most decisive motives for attempted suicide (e.g., Brodsky, Malone, Ellis, Dulit, \& 
Mann, 1997; Hawton, Haigh, Simkin, \& Fagg, 1995; Michel, Valach, \& Waeber, 1994).

By distinguishing between joint actions, projects, and career, we account for the fact that goal-directed processes can be seen in different forms such as short-term actions lasting a few minutes; mid-term projects consisting of days, weeks, and months; and career being measured in years. We asked whether the joint organization of goaldirected processes in suicide attempts are evident and illustrated in patients' narratives about the attempt. We also asked whether these illustrations can assist in extending the conceptualization of suicide and attempted suicide as a social and goal-directed process beyond the event itself.

It has been suggested that a new approach to suicide behavior is necessary. The establishment of a clear relation between suicidal behavior and other problematic behaviors and psychological states and psychiatric disturbances, such as depression, has proven difficult (Kienhorst, De Wilde, \& Diekstra, 1995). The authors of this study propose a shift in objective from suicidal behavior as a single dependent variable to suicidal behavior as part of a larger concept, such as a style of reactions to problematic situations.

This study is informed by a contextual action approach described elsewhere (e.g., Young, Valach, \& Collin, 2002) and is based on a theory of goal-directed action (von Cranach, Kalbermatten, Indermuehler, \& Gugler, 1982; von Cranach, \& Valach, 1986). In short, action is seen as goal-directed behavior, cognitively and socially steered, controlled and regulated by feedback and feed forward processes. In the present article, we describe and illustrate various forms of social embedding of the patients' narratives of suicide attempts as described in a psychotherapeutic interview.

\section{METHOD}

This study was informed by a qualitative research method that is grounded in the action theory described above (Valach, Young, \& Lynam, 2002). In this case, the immediate action was a psychotherapeutic interview in which the suicide narrative emerged. This narrative gave us access to the construction of the suicide act and related projects and careers. Data from three perspectives on action were gathered: the manifest behavior in the interview itself; the patient's internal processes gathered immediately after the interview through a video playback procedure; and the social meaning of the action (and the projects and career) attributed to the phenomena discussed by the patient, the psychotherapist, and the research team. The present analysis uses data from the interviews only.

\section{Sample}

A consecutive sample of 40 patients hospitalized because of the health consequences of their suicide attempt comprised the participants in this study. A psychotherapist invited these patients to participate in this study. Their participation consisted of talking to a psychotherapist about their suicide attempt. The patient participation rate for the study was high, although we did not undertake to obtain a representative sample. The only systematic selection bias was incurred when some of the patients who had been admitted to the in-patient general hospital where they were recruited for the study were relocated to a psychiatric hospital, and thus not available to be interviewed. Consequently, we did not have any patients diagnosed with an acute psychotic disorder. The sample consisted of 25 women, 15 men (mean age $=42$ years, range 17-80). The interviews were conducted by psychotherapists (eight medical doctors, one psychologist).

\section{Setting}

The interviews were conducted in a psychiatric outpatient clinic, a building about 100 meters away from the ward where the patients were in care. In the interview room the patients were exposed to two video cam- 
era recorders, and TV monitors. In addition, the Skin Conductance Reactivity (SCR) (not used in this analysis) was monitored during the interview for which the patients as well as the psychotherapists were equipped with a small electrode attached to their palm. Nevertheless, the setting was private and calm.

\section{Procedure}

The interview, in which the patients were asked to describe how it came about that they had attempted suicide, lasted between 30 and 60 minutes and was video recorded. The patients were encouraged to talk about everything they considered related to their suicide attempt. The interviewers prompted them for details, asked them to clarify unclear points, and were emphatic and emotionally supportive. Immediately after the interview, the videotape was shown to the patient by another psychotherapist. It was stopped every 1.5 to 2.5 minutes at the end of a meaningful unit. The second psychotherapist then asked the patient to report on feelings, thoughts, or sensations he or she had during the interview. Further, patients were encouraged to provide additional information to what was already said or seen on the video.

\section{Ethical Considerations}

This project was supported by the Swiss National Research Foundation and approved by the Psychiatric Out-patient Clinic and the relevant departments of the University Hospital, Berne, where the patients were hospitalized, and by the ethics committee of the Swiss National Research Foundation. The patients were asked in the hospital whether they would like to participate in a study, which was described to them. Prior to the interviews the patients were again informed about the procedure in every detail and asked to sign a permission to videotape the interviews. They were informed that these videotapes would be seen by project collaborators, then transcribed and analyzed for research purposes. They were also asked for permission to allow us to quote substantial parts of these interviews in an anonymous form in scientific professional publications.

\section{FINDINGS}

We sought to determine whether and how patients describe the processes of their suicide attempt as individual or joint goaldirected processes and to illustrate how these processes are organized. We found that all study patients described their suicide attempt as a joint process. In only three of the 40 cases was a relationship not predominantly involved in the suicide career.

The patients' narratives illustrate the specific projects and careers in which the suicide attempts were embedded. These narratives were mostly about relationship careers that reflected the long-term processes operational in their suicide actions. The relationship careers were with parents $(n=14)$, including specifically mothers $(n=6)$ and fathers $(n=2)$. However, for the majority of patients, their partners were involved $(n=$ $21)$, including boyfriends $(n=6)$, girlfriends $(n=5)$, wives $(n=3)$, husbands $(n=6)$, or children $(n=3)$. Further, for some patients, the suicide attempt was embedded in a relationship project that was part of the longerterm relationship career $(n=6)$. Finally, the specific actions that preceded the suicide attempt were narrated as social actions; for example, arguing, or ending a relationship ( $n=$ 7). For some patients, the suicide processes were embedded in a social identity project $(n=6)$.

\section{Suicide Attempts as Action, Project, and Career}

We begin by illustrating the social embedding of suicide in which the order of career, projects, and actions can be observed. We found in these narratives that the suicide attempts were framed in social terms that reached far beyond their social causation. This framing included a narrative of the sui- 
cide career, which, from our perspective, is social in its basic conceptualization. The narratives of the suicide attempt were also presented as social projects that included both suicide actions and being a part of a suicide career. In each of the following examples, narrative evidence of the suicide career, project, and action is provided.

\section{PATIENT ID NO. 1, FEMALE STUDENT, MID TWENTIES}

CAREER: "I like my mother very much and don't wrap up [hide] my criticism well just because I have to, but also because I don't want to hurt her. This developed over the years. It is because I am all my mother has."

Here the patient described a long-term career issue; that is, the relationship with her mother. In addition, she referred to the longterm relationship to her boyfriend. She described these relationships as closely related to her suicide attempt.

PROJECT: "I was in a deep lover's grief for several months."

The patient's suicide project represents a certain phase of the relationship to her boyfriend, particularly the parting sequences and the pain it caused.

ACTION: "After the argument with my mother I went to the bathroom, where I had normal razor blades and I looked at them and thought whether it would hurt if one cuts oneself. Afterwards I tried it; first on the upper arm and on all the important places and it did not hurt at all. ... I tried at first here [indicates upper lower arm] and it did not hurt. Then I watched how it bled and it was nothing special. And then I cut myself at the important places [indicates wrist] and put the arm into water and watched the rings of rising blood, which was pretty. I was more or less simply watching myself."
The action is the unit including the suicide action step itself in which the patient dealt with a confrontation with her mother in an extreme way. Following this sequence she became frightened and told her mother on the telephone what she had done.

This patient described a suicide attempt, which she executed after her mother left and which was terminated by calling her mother and telling her about it. It was part of both a relationship project with her boyfriend and a relationship career with her mother. Thus, apart from the actual act of cutting, this patient's suicide attempt was well embedded in social processes and it served a certain function in these goal-directed processes. It may be said that it is socially motivated by the broken relationship and triggered by the argument with her mother.

\section{PATIENT ID NO. 2, HEARING-CHAL- LENGED MALE, 18 YEARS OLD}

CAREER: "I live with my adoptive mother. In my heart I am very sad because my real mother abandoned me. She did not want any children. I was seven when I was adopted together with my sister. My mother drank a lot, just like my father."

The patient described his suicide as embedded in his inhibited and unsuccessful relationship career with his mother.

PROJECT: Prior to the suicide attempt, the patient stayed alone at home after an argument with his adoptive parents: "My adoptive mother and myself we had an argument together and then I stayed alone. They [the family] went to my cousin's and I told them I want to stay at home"

The patient stole some money and lied about it. "When my adoptive father came back I took the money without telling. Then we went to do some shopping, went for lunch and came back and he asked where the money is. I told him a lie."

The patient became frightened the next day, returned the money and got drunk. "I was 
alone the next day. I became frightened that there is going to be an argument. So I put the money in an envelope and wrote a letter. I opened a bottle and got drunk and became 'crazy.'"

The patient's father threatened to "kick [the patient] out." The patient packed his suitcase. "When my adoptive parents returned I gave them the envelope and went back to my room. I heard my adoptive father saying 'who steals money must go.' Then I packed my suitcase and there was peace again because the money was returned and I did not do anything with it. There was no beating, nothing."

The suicide project was described as part of the patient's conflict with his adoptive parents.

ACTION: The patient prepared his suicide weapon and actualized an inner suicide dialogue. "Then I was in my room, got the knife and put it on the table. I've told my (adoptive) mother I am going to hang myself, shoot myself in head or cut my artery. She said she doesn't care and I should do it."

The patient narrated the crucial suicide action step. "So I've done it with a knife. As my [adoptive] father said I should stay then I've gone on with cutting. Just a quick cut. Afterwards it became painful and I thought that I am going to kill myself. Then I did not feel well. Blood just run down. I bandaged the wound. I felt dizzy because I've drunk some wine, otherwise I would have not been able to do it. I really had the thought that I am going to kill myself."

The patient announced his intended suicide action to his parents and then executed it. Similar to the first case, this patient's suicide action was also embedded in a parent-child relationship career with his adoptive and his natural mother as well as in a conflict project with his adoptive parents. The patient communicated his suicide intention but was challenged by his mother to do it. His suicide attempt was closely embedded in these joint processes.

\section{The Social Embeddedness of Suicide Attempts}

The long-term processes of relationship careers were reported in the patients' narratives as operational in their suicide actions and projects. These relationships often included parents, such as described by this patient, a 17-year-old girl:

I have problems with my parents. My father left when I was three years old and was promising things all the time, such as that he is going to take me to the movies, and he never showed up. He came back a year ago and is living with us now. He is a Moslem and according to his ideas a girl of my age is not allowed to have a boyfriend and go out. He thinks he can bring me up in this way. When he has a problem, he drinks and when he is drunk he comes home and tries to explain to me that he loves me and that is too much for me, because he is not a father for me. When he and my mother have a problem with my mother she takes it out on me. Now she is ill. She had stomach reduction surgery and now she is depressed and jumpy and takes it out one me.

For the majority of patients, their partners were involved, as illustrated in the narrative of a woman in her early 20s about her boyfriend:

I was hanging on that man a lot because I went through three sexual abuse attempts. I was six, fifteen, and sixteen. I felt that he would not do it. As far as this is concerned he was misusing my trust. Two months ago it nearly happened again. This time it was his best friend.

Equally often the relationship careers also included wives, as illustrated in the narrative of a male patient in his early 30 s: 
My wife did not feel well. She listened to loud music and did not watch television. I cooked all of the time. After some time, she said that I should go. I said that I did not do anything, I didn't do anything with the other woman. I said that we should continue to live as we always had and should try to begin again. She said that I destroyed her. Once we went to the cemetery, to the grave of my aunt and she suddenly started screaming and crying. She said again and again that I've destroyed her ... I did not say anything. I thought that it is better to keep quiet. She told me I should leave her. So I've slept in the garden. Next day I went to work and when I came back she said again I should leave.

In some narratives the suicide processes were explicitly embedded in a social identity career involving others in an unspecified way, as illustrated in the following quotation from a 32-year-old male patient:

The whole time I had relationship problems with women. Earlier, I had problems because I was too fat. Now I have problems not because I am too thin but because I am too extreme. They are frightened. If I want to go away over the weekend into the mountains in order to experience something, there is no time for a girlfriend. This leads to problems. Everything is difficult. Then I am also afraid of being at home. I am frightened of being alone. I often feel as if I were in a box. I have it nice at home ... well I like it but I feel like I am in a box. I have a desire to go out, I am a freedom loving person.

In a similar manner, the patients' narrated stories of the suicide attempt embedded in projects were mostly relationship projects. These projects are parts of the relationship careers described above. The relationship projects, including the breaking up of relationships, were often operational in the pa- tient's crisis. However, they were not always presented or understood by the patients as causal in a way that suggested the relationship facilitated the suicide, or even as a reason for suicide. For example, although the following 18-year-old patient considered suicide, she would not do it because of her relationship. Of interest are situations in which relationship projects functioned in such a way that the patient felt unable to communicate her or his urgent problems:

A colleague of mine is there [at a horse cart competition]. I had already gone with him to England. I go with him to the shows and competitions. Also I go to those near by. I just felt totally not understood. ... I met him in the Spring. At that time I did not feel well either. He looked after me and I felt good. I thought that it is a place for me where I can always go and feel understood [by this man and his wife].... Suddenly, I felt that this changed. I didn't know ... whenever he asked how I am, I either said that I am fine which was not true or I said I am not well. I thought that it was boring for them. I was very disappointed that they didn't understand me any more.

At other times these joint actions and action steps prior to the suicidal action were critical because patients were experiencing pressure. Very often the patients were critical because a relationship was ending or being terminated, for example, a 30-year-old male patient stated:

I realized on the phone, talking to my new girlfriend, that it is not going the same as before. We were suddenly arguing and had different ideas. Something was disturbing me. When I came back we met and she told me that it is not satisfying to her like this, that she feels challenged and realizes that I have a problem. I realized that myself. ... It was all too much for me ... the new job, new flat... Some weeks later she told me that she can't go 
on like this ... and that it would be the best if we went each our own ways again.

\section{DISCUSSION}

Our interest is in underlining the joint social issues referred to by the study interviewees in an attempt to examine our propositions about the joint social nature of suicide processes. The findings reflect our proposition that suicide and suicide attempts are social processes and can be readily seen as joint actions, joint projects, and joint careers (Michel \& Valach, 1997); however, the composition of the suicide systems in regard to its joint nature varied across patients.

These findings illustrate what has been found in other studies; that is, that relationship action, projects, and career are critical in the way patients understand suicide attempts (Brodsky et al., 1977). The cumulative evidence suggests that a new conceptualization of the social processes in which suicide attempts are embedded is possible.

This is a stance we also support. First, we recognize that relationships plays, or are seen as playing, an important role in suicide and suicide attempts. We would add, following on the evidence presented in this study, that it is not just mismanaged or broken relationships but a whole series of relationship developments to which suicide is described as an alternative. We have illustrated, for example, that people, after a suicide attempt, often describe their whole life as characterized as not being part of joint projects, such as family projects, or not being included in parentchildren joint actions.

Second, a new conceptualization relies on the recognition by therapists, well attuned to working with narratives, that a suicide or suicide attempt should not be seen as an alternative to the person's organization of action, projects, and career related to relationships, but it is an action, project, and career itself, which includes relationship dimensions.

Third is the social nature of suicide processes. It often has been proposed that emotions and affective behavior are social phenomena with social roots, social involvement, and social consequences (e.g., Harré, 1986), and affective regulation can be seen as social process. Thus it is understandable that suicide attempters report significantly higher levels of affect disregulation and a greater number of different types of self-mutilation behaviors than others (Zlotnick, Donaldson, Spirito, \& Pearlstein, 1997). It is known that this type of behavior is particularly common in people who experienced difficult parenting careers (Hollis, 1996; Johnson et al., 2002). Some studies indicate that suicide attempts not only follow a difficult or unsuccessful joint relationship project but also that people after a suicide attempt also show a very difficult joint relationship career, indicated by low socialization scores (e.g., Engstroem et al., 1996). The line of evidence regarding the salience of relationships is suicide attempts is further supported by research on unemployment as a joint relationship project (Runeson, Eklund, \& Wasserman, 1996); when a vital relationship is lacking (Klee, 1995); and the relationship between sexual abuse in childhood and suicide ideation in men (Boudewyn \& Liem, 1995).

The first step in bringing a new conceptualization to suicide research that recognizes the relevance of social embeddedness consists of considering Valsiner and van der Veer's (2000) views, and particularly the solution proposed by Valsiner (1994). In this constructionist model, the individual's uniqueness and relatedness with social units are emphasized. Other helpful approaches include the dialogical approach outlined by Markova (2003), which provides a basis for reflecting the social processes in individual action. We believe that working with the concepts of joint goal-directed systems in the form of joint actions, projects, and careers (Valach, Young, \& Lynam, 2002) is a further step in subjecting this issue of social processes within individual action to empirical analysis for the topic of suicide.

\section{Limitations}

Several shortcomings of this study may be initially apparent. The sample was rela- 
tively small; the interview procedure was unstructured; and the content analysis was descriptive rather than categorical. However, as this was a qualitative exploratory study in which lengthy interviews were transcribed and analyzed, we consider the 40 interviews a satisfactory amount. Obviously we cannot assume that the statements we generated based on these interviews will reach universal validity. We cannot even assume that these individuals represent all types of suicide, or all types of not completed suicides. Consequently, we suggest that these data might be typical for suicide attempters but not for completed suicide acts. Thus the issue of fatality of the means used is not of primary relevance in dealing with a person after an incomplete suicide act.

In addressing the content of the narratives, we were interested in identifying the system of how suicide processes are organized in terms of actions, projects, and careers. The analysis moved in a hermeneutic between the theory and the data, keeping in mind that the topic we wanted to address was the joint nature of the processes patients narrated about their suicide attempt. A possible objection is that it is known from attribution research that patients' explanations can be seriously distorted. However, in attribution research subjects are asked to explain or reason about a certain event or action. This is not the case in this study. We did not ask the patients why they attempted suicide, nor do we assume that the description they provided addressed the causes of the suicide attempts.

\section{CONCLUSION}

Suicide is often described as a final step in an identity project or career. It is a dramatic intervention at the level of our biological existence. But biological death is not as experiential a concept as the concept of our death as related to social identity projects and career. It is the person more than the body that dies. Death, suicide, and suicide attempts are social enterprises, as many theories tell us; however, this knowledge is often not understood when dealing with suicide patients.

The statement that a suicide action is a social action and in fact often a joint action, either in a direct or an indirect way, can be disputed because, in everyday understanding, calling it a social action connects it to the issue of responsibility. However, the understanding of the social nature of suicide is crucial for understanding the patients' narratives. It could be argued that the issue of suicide as a social process was well examined by Durkheim and has been established, but our suggestion is not that suicide is caused by some social variables, be it a social group or the degree of social integration. Our proposition is that suicide processes are actions and mainly joint action, which is a view closer to Weber (1949) than Durkheim. In summarizing the 40 cases included here it might appear that all of them fit the proposed conceptual frame, making the frame irrefutable, yet we saw differences. In some patients the suicide career is less of a joint career than in others; and in some, the suicide action was not a joint action. Additionally, we can see that the type of these joint processes can be specified and addressed in suicide prevention attempts. The findings presented here address one aspect of this view, which we would like to see as promoting a paradigm shift in suicide research. Given the complexity of this topic, we have outlined some of the issues in other publications and presentations (Michel, Dey, Stadler, \& Valach, 2004; Michel et al., 2002; Michel \& Valach, 2001; Valach, Michel, Dey, \& Young, 2002; Valach, Michel, Young, \& Dey, 2002; Young \& Valach, 2002 ), in order to develop a more comprehensive picture. In this report we deal with the narratives of the patients only. Future research may consider examining how persons who have attempted suicide construct these narratives of goal-directed processes in ways that are related to treatment and prevention. 


\section{REFERENCES}

Bandura, A. (1986). Social foundations of thought and action: A social cognitive theory. Englewood Cliffs, NJ: Prentice Hall.

Boudewyn, A. C., \& Liem, J. H. (1995). Childhood sexual abuse as a precursor to depression and self-destructive behaviour in adulthood. Fournal of Traumatic Stress, 8, 445-459.

Brodsky, B. S., Malone, K. M., Ellis, S. P., Dulit, R. A., \& Mann, J. J. (1997). Characteristics of borderline personality disorder associated with suicidal behavior. American Fournal of Psychiatry, 154, 1715-1719.

Durkheim, E. (1951). Suicide. Glencoe, IL: Free Press. (Original work published 1897)

Engstroem, G., Alsen, M., Gustavsson, P., Schalling, D., Iraeskman, R., \& Bendz, L. (1996). Classification of suicide attempters by cluster analysis: A study of the temperamental heterogeneity in suicidal patients. Personality \& Individual Differences, 21, 687-695.

Harré, R. (ED.). (1986). The social construction of emotions. Oxford: Basil Blackwell.

Hawton, K., Haigh, R., Simkin, S., \& FAGG, J. (1995). Attempted suicide in Oxford University students, 1976-1990. Psychological Medicine, 25, 179-188.

Hollis, C. (1996). Depression, family environment, and adolescent suicidal behavior. Fournal of the American Academy of Child and Adolescent Psychiatry, 35, 622-630.

Johnson, J. G., Cohen, P., Gould, M. S., Kasen, S., Brown, J., \& Brook, J. S. (2002). Childhood adversities, interpersonal difficulties, and risk for suicide attempts during late adolescence and early adulthood. Archives of General Psychiatry, 59, 741-749.

Kienhorst, I.W.M., De Wilde, E. J., \& Diekstra, R.F.W. (1995). Suicidal behaviour in adolescents. Archives of Suicide Research, 1, 185209.

KleE, H. (1995). Drug misuse and suicide: Accessing the impact of HIV. AIDS Care, 7(Suppl. 2), S145-S155.

Maris, R. W. (1989). The social relations of suicide. In D. J. Jacobs \& H. N. Brown (Eds.), Suicide: Understanding and responding (pp. 87125). Madison, CT: International Universities Press.

Maris, R. W. (1997). Social suicide. Suicide and Life-Threatening Behavior, 1, 41-49.

Markova, I. (2003). Dialogicality and social representations: The dynamics of mind. Cambridge: Cambridge University Press.

Michel, K., Dey, P., Stadler, K., \& VALACH, L. (2004). Therapist sensitivity towards emotional life-career issues and the working alli- ance with suicide attempters. Archives of Suicide Research, 8, 203-213.

Michel, K., Maltsberger, J. T., Jobes, D. A., Leenaars, A. A., Orbach, I., Stadler, K., ET AL. (2002). Discovering the truth in attempted suicide. American Journal of Psychotherapy, 56, 424-437.

Michel, K., \& Valach, L. (1997). Suicide as goal directed action. Archives of Suicide Research, 3, 213-221.

Michel, K., \& Valach, L. (2001). Suicide as goal-directed action. In $\mathrm{K}$. van Heeringen (Ed.), Understanding suicidal behaviour: The suicidal process approach to research and treatment (pp. 230254). Chichester: Wiley.

Michel, K., Valach, L., \& Waeber, V. (1994). Understanding deliberate self-harm: The patients' views. Crisis, 15, 172-186.

OAKLEY, R. (2004). How the mind hurts and heals the body. American Psychologist, 59, 29-40.

Runeson, B., Eklund, G., \& Wasserman, D. (1996). Living conditions of female suicide attempters: A case-control study. Acta Psychiatric Scandinavica, 94, 125-132.

Valach, L., Michel, K., Dey, P., \& Young, R. A. (2002). Self-confrontation interview with suicide attempters. Counselling Psychology Quarterly, 15, 1-22.

Valach, L., Michel, K., Young, R. A., \& Dey, P. (2002). Attempted suicide stories: Suicide career, suicide project, and suicide action. In L. Valach, R. A. Young, \& M. J. Lynam Action theory: A primer for applied research in the social sciences (pp. 153-171). Westport, CT: Praeger.

Valach, L., Young, R. A., \& Lynam, M. J. (2002). Action theory: A primer for applied research in the social sciences. Westport, CT: Praeger.

Valsiner, J. (1994). Culture and human development: A co-constructionist perspective. In P. van Geer, L. P. Mos, \& W. J. Baker (Eds.), $A n-$ nals of theoretical psychology (vol. 10, pp. 247-298). New York: Plenum.

Valsiner, J., \& van der Veer, R. (2000). The social mind: Construction of the idea. Cambridge: Cambridge University Press.

von Cranach, M., Kalbermatten, U., Indermuehler, K., \& Gugler, B. (1982). Goaldirected action. London: Academic Press.

von Cranach, M., \& Valach, L. (1986). Action theory. In R. Harré \& R. Lamb (Eds.), The dictionary of personality and social psychology. Oxford: Blackwell Reference.

Wittgenstein, L. (1999). Philosophical investigations (3rd ed.). Englewood Cliffs, NJ: Prentice-Hall. 
Young, R. A., \& Valach, L. (2002). The self-confrontation interview in suicide research, intervention, and prevention. Lifenotes, 7, 12, 14.

Young, R. A., Valach, L., \& Collin, A. (2002). A contextualist explanation of career. In D. Brown \& Associates, Career choice and development (4th ed., pp. 206-252). San Francisco: Jossey-Bass.

WEBer, M. 1903-1917 (1949). The methodology of the social sciences. E. Shils \& H. Finch (Eds.). New York: Free Press.
Zlotnick, C., Donaldson, D., Spirito, A., \& Pearlstein, T. (1997). Affect regulation and suicide attempts in adolescent. Fournal of the American Academy of Child \& Adolescent Psychiatry, 36, 793-798.

Manuscript Received: Jun 26, 2005

Revision Accepted: February 7, 2006 